\title{
A Cross-sectional Study of Central Corneal Thickness in Dry Eye Disease Patients in a Tertiary Centre in South India
}

\author{
Minnu Lekshmi R. ${ }^{1}$, Rajakumari Murugesan², Vignitha K. ${ }^{3}$, Aditi Pandey ${ }^{4}$, Heena Dharamdasani ${ }^{5}$ \\ 1, 2, 3, 4, 5 Department of Ophthalmology, Chettinad Hospital and Research Institute, Kelambakkam, Tamil Nadu, India.
}

\section{ABSTRACT}

\section{BACKGROUND}

Dry eye disease is one of the most common presentation in hospital with varied presenting complaints and which can lead to various complications. Study is done on 200 eyes diagnosed with dry eyes in a tertiary centre in South India using Schirmer; and tear break up time test. Their central corneal thickness is measured using specular microscopy. The correlation of dry eye disease and central corneal thickness is assessed. Dry eye disease diagnosed using Schirmer test showed a strong correlation with the central corneal thickness. A significant reduction in central corneal thickness was observed in dry eyes disease diagnosed with Schirmer disease. The factors affecting dryness includes inflammatory component and evaporating component. Based on my study the results of dry eyes due to inflammation of eye can be considered to have more association to the pathogenesis in relation to central corneal thickness. Inflammation decreases the eyes' ability to produce normal tear.

\section{METHODS}

200 eyes of 100 patients who presented in hospitals diagnosed with dry eye disease were included in the study. The central corneal thickness of these patients was measured and corelated with the degree of dryness using Shermer's test and tear film break up time

\section{RESULTS}

A statistical significance was observed between the inflammatory component causing dry eyes and the CCT values

\section{CONCLUSIONS}

There is a significant association between the central corneal thickness and dry eye diseases.

\section{KEY WORDS}

Central Corneal Thickness, Schirmer's Test, TBUT.
Corresponding Author: Dr. Rajakumari Murugesan, Professor,

Department of Ophthalmology, Chettinad Hospital and Research Institute, Kelambakkam, Tamilnadu, India.

E-mail:minnulekshmir@gmail.com

DOI: $10.14260 /$ jemds $/ 2022 / 42$

How to Cite This Article:

Lekshmi MR, Murugesan R, Vignitha K, et al. A cross-sectional study of central corneal thickness in dry eye disease patients in a tertiary centre in South India. J Evolution Med Dent Sci 2022;11(01):218221, DOI: $10.14260 / \mathrm{jemds} / 2022 / 42$

Submission 27-12-2021,

Peer Review 20-01-2022,

Acceptance 27-01-2022,

Published 31-01-2022.

Copyright (c) 2022 Minnu Lekshmi R. et al. This is an open access article distributed under Creative Commons Attribution License [Attribution 4.0 International (CC BY 4.0)] 


\section{BACKGROUND}

Tear film forms the protective cover over the cornea. Conjunctive, is made of three layers, the outer lipid layer, intermediate aqueous layer and the inner mucin layer. Mucus layer is $0.2 \mu \mathrm{m}$ in thickness. The mucin layer is mainly secreted by goblet cells in conjunctiva. Aqueous layer is secreted from the main and accessory lacrimal glands of Krause and Wolfring. The aqueous layer is mainly composed of proteins, electrolytes, peptide growth factors have thickness of $7 \mu \mathrm{m}$ that consists of water and antimicrobials (lysozymes)

The uppermost layer is a lipid layer, mainly secreted by meibomian glands. Lipid layer reduces evaporation by $95 \%$ from ocular surface. ${ }^{1}$

The tear film protects cornea from drying, helps to maintain refractive power of cornea, protects from eye infection, and increases permeability of oxygen.

\section{Dry Eye}

Factors that result in ocular inflammation and the inflammation of tear glands can result in dryness of eye. Inflammation decreases the eyes' ability to produce normal tear that has function of protecting eye and to keep it lubricated. ${ }^{2}$ Dry eye disease is abnormality of the tear film and is now considered as multifactorial disease of the tears and ocular surface. Severe dryness has severe damage to the ocular surface.

Most common causes of dry eyes include diseases such as rheumatoid arthritis, Sjogren's syndrome, thyroid disease, lupus, blepharitis, entropion, environment of wind, dry climate smoke, continuous looking at computer screen, using contact lenses for long time, having refractive eye surgery such as LASIK.

The risk factors causing DEDs are: older age group, female, woman over menopause, smoking is one of most important risk factor, autoimmune disorders, and environmental factors. Patient usually presents with complaints of burning sensation, itching due to dryness, foreign body sensation and excessive photophobia and occasionally with dryness. When the eyelids blink the tear layers will be spread throughout and protects the eye and also provides lubrication to eye and prevents dry eyes. Dry eyes disease is mostly caused due to either inadequate secretion of secretion from the lacrimal glands or due to excessive evaporation of the tear film. Severe untreated inflammations can cause damages to the lacrimal gland and ocular surface thereby causing lowering of tear production and altered corneal barrier function.

\section{Diagnosis of Dry Eyes}

Clinically using slit lamp, dry eyes is diagnosed with meniscus tear height, Schirmer's test, rose bengal staining, fluorescein dye test, tear film break up time. The tests used in our study are Schirmer's test and tear film break up time. Schirmer's test 1: where the total tear secretion i.e., both reflex and basal secretion is taken into account

- Normal range with no dryness is $10-15 \mathrm{~mm}$

- Dry eye
- $\quad$ Mild dryness 9-14 mm

- Moderate dryness 4-8 mm

- $\quad$ Severe dryness $<4 \mathrm{~mm}$

- Tear film break up time <TBUT

First dry spot from the last blink is noted in patients' eyes are stained with fluorescein dye. The test is for stability of the tear film

Wetting time $>20$ second is considered as tear film stability to be normal

TBUT averages between $25-30$ seconds in normal individuals

TBUT $<10$ seconds is considered as significant tear film instability.

Most commonly seen in dry eyes

The measurement of central corneal thickness (CCT) helps to assess the corneal health. Pachymetry is used to assess the central corneal and also the endothelial pump mechanism. Central corneal thickness can be assessed using a specular microscopy. Factors affecting central corneal thickness include younger patients, diabetic patients and male patients.

The principle of specular microscopy includes the distance between the anterior and the posterior surfaces of cornea and depends on focusing of light rays through front back cornea. It's a non-invasive method and operator independent. Specular microscope can be used for simultaneous measurement of cell count.

The purpose of the study was to assess CCT in patients with dry eye disease in a tertiary centre in South Indian population.

\section{METHODS}

200 eyes of 100 patients who presented in hospitals with complaints of foreign body sensation, irritation, redness and burning sensation were enrolled for study. Sample size calculated as follows: Formula-

$n=\frac{4 p q}{d 2}$

$\mathrm{n}=$ sample size $=123$

$\mathrm{p}=$ prevalence $=31$

$\mathrm{q}=100-\mathrm{p}=69$

$\mathrm{d}=$ allowable error $=10$

Based on the prevalence of dry eye disease in the area, 123 was the sample size calculated.

\section{Inclusion Criteria}

All patients with dry eye disease

\section{Exclusion Criteria}

- Patients with ocular surface disease.

- Patients on chronic topical medications.

- Patients after ocular surgeries.

- Patients who underwent refractive surgery.

- Patients with auto immune disorders. 
Cross-sectional study including patients of both sexes was conducted. Patients underwent ocular examination. Uncorrected and best corrected visual acuity was checked, slit lamp examination was done for detection of any corneal abnormality to exclude patients with ocular surface disorders, anterior segment was examined. The Schirmer's test is done and tear film break up time was measured for all patients and documented. Schirmer's test 1: where the total tear secretion i.e., both reflex and basal secretion is taken into account.

Two strips were labelled as right and left. Strip is bent at the notch and placed over the centre of the lower eyelid. Patient is asked to keep the eyes closed.

\section{Measurement of the Strip is Noted after 5 Minutes. ${ }^{3}$}

- Normal wetting 10-15 mm

- Dry eye

- $\quad$ Mild dryness 9-14 mm

- Moderate dryness 4-8 mm

- $\quad$ Severe dryness $<4 \mathrm{~mm}$

\section{TBUT}

Where the first dry spot from the last blink, patients' eyes are stained with fluorescein dye and the time of appearance of the first dry spot is documented. The test is for stability of the tear film

Wetting time $>20$ second is considered as normal tear film stability

TBUT averages between $25-30$ seconds in normal individuals

TBUT $<10$ seconds is considered as significant tear film instability.

Most commonly seen in dry eyes

Central corneal thickness was measured for all the patients using specular microscopy and documented. The central corneal thickness helps to assess the corneal health. Pachymetry is used to assess the central corneal and also the endothelial pump mechanism. Central corneal thickness can be assessed using a specular microscopy. Factors affecting central corneal thickness include younger patients, diabetic patients and male patients.

\section{Statistical Analysis}

Statistical analysis was done using $t$ test and ANOVA test

\section{RESULTS}

\section{Descriptive Statistics}

Sample Size: N=200

\section{Mean Age}

$47.40 \pm 15.04$

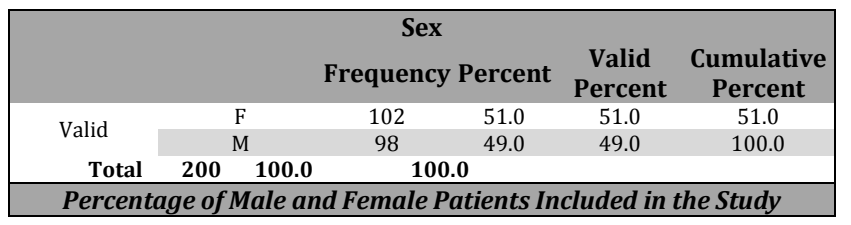

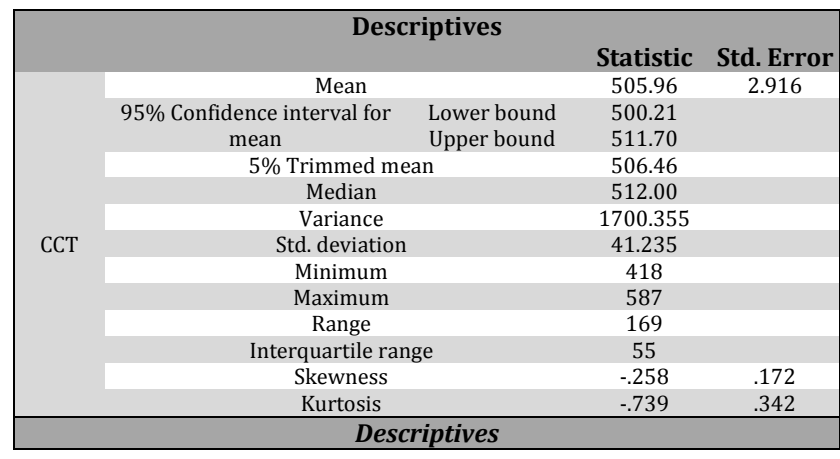

The table describing the mean range of values of CCT calculated based on the selected population of the patients diagnosed with dry eye disease.

\section{T-Test}

\begin{tabular}{|c|c|c|c|c|c|}
\hline \multicolumn{6}{|c|}{ Group Statistics } \\
\hline & TBUT Code & $\mathbf{N}$ & Mean & Std. Deviation & $\begin{array}{l}\text { Std. Error } \\
\text { Mean }\end{array}$ \\
\hline \multirow{2}{*}{ СCT } & Normal & 41 & 496.68 & 38.190 & 5.964 \\
\hline & Abnormal & 159 & 508.35 & 41.765 & 3.312 \\
\hline \multicolumn{6}{|c|}{ Group Statistics } \\
\hline
\end{tabular}

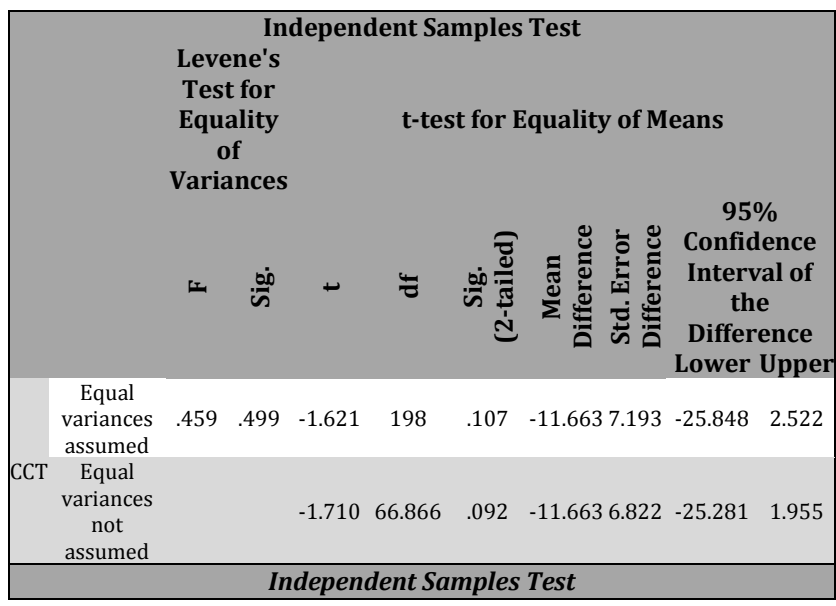

Test association using t-test to evaluate the association between TBUT and CCT by mean difference showed a statistically significant observation with $\mathrm{t}=-1.710, \mathrm{p}=0.046$

\section{Oneway}

\begin{tabular}{|c|c|c|c|c|c|c|c|c|}
\hline \multicolumn{9}{|c|}{$\begin{array}{l}\text { Descriptives } \\
\text { CCT }\end{array}$} \\
\hline & \multirow[t]{2}{*}{$\mathbf{N}$} & \multirow[t]{2}{*}{ Mean $_{\text {I }}$} & \multirow[t]{2}{*}{$\begin{array}{c}\text { Std. } \\
\text { Deviation }\end{array}$} & \multirow[t]{2}{*}{$\begin{array}{c}\text { Std. } \\
\text { nError }\end{array}$} & \multicolumn{2}{|c|}{$\begin{array}{c}95 \% \\
\text { Confidence } \\
\text { Interval for } \\
\text { Mean }\end{array}$} & \multirow[t]{2}{*}{ Minimum } & \\
\hline & & & & & $\begin{array}{l}\text { Lower } \\
\text { Bound }\end{array}$ & $\begin{array}{l}\text { Upper } \\
\text { Bound }\end{array}$ & & Maximum \\
\hline Normal & 6 & 483.00 & 39.759 & 16.232 & 441.28 & 524.72 & 432 & 522 \\
\hline Mild & 34 & 511.79 & 37.761 & 6.476 & 498.62 & 524.97 & 444 & 580 \\
\hline Moderate & 140 & 511.03 & 38.614 & 3.263 & 504.58 & 517.48 & 423 & 587 \\
\hline Severe & 13 & 485.08 & 46.988 & 13.032 & 456.68 & 513.47 & 418 & 570 \\
\hline $\begin{array}{c}\text { Very } \\
\text { severe }\end{array}$ & 7 & 434.57 & 8.182 & 3.093 & 427.00 & 442.14 & 423 & 446 \\
\hline Total & 200 & 505.96 & 41.235 & 2.916 & 500.21 & 511.70 & 418 & 587 \\
\hline & & & & script & tives, & & & \\
\hline
\end{tabular}

\begin{tabular}{|ccc|ccc|}
\hline & \multicolumn{5}{c|}{ ANOVA } \\
& Sum of & CCT & & & \\
& Squares & df & Mean & F & Sig. \\
Between groups & 49260.513 & 4 & 12315.128 & 8.306 & .000 \\
\hline Within groups & 289110.082 & 195 & 1482.616 & & \\
\hline Total & $\mathbf{3 3 8 3 7 0 . 5 9 5}$ & $\mathbf{1 9 9}$ & & \\
\hline \multicolumn{7}{c}{ ANOVA/CCT } \\
\hline
\end{tabular}


Based on test of association using one -way ANOVA to evaluate the association between Schirmer's and CCT by mean difference showed a statistically significant observation $f=8.306, p=0.030$.

\section{DISCUSSION}

The above study suggested that a significant reduction of central corneal thickness was observed in cases of dry eye disease. In a study with a total of 200 eyes were chosen with a mean age of $47.40 \pm 15.04$. Dry eye disease was diagnosed with Schirmer's test and TBUT. Test association using t-test to evaluate the association between TBUT and CCT by mean difference showed a statistically significant observation with $\mathrm{t}=-2.037, \mathrm{p}=0.046$.

While based on test of association using one -way ANOVA to evaluate the association between Schirmer's and CCT by mean difference showed a statistically significant observation $f=2.730, p=0.030$. The significant reduction in corneal thickness is observed in patients diagnosed with dry eyes with Schirmer's test and TBUT test with a significant $p$ value. The physiological status of cornea can be assessed by measuring the central corneal thickness. Specular microscopy can be used to measure the central corneal thickness. ${ }^{4}$ Based on the study by Noora Mauwafak Ali, et al. central corneal thickness was observed to be significantly reduced in patients with dry eyes, compared to normal eyes. Sanchis-Gimeno et al. showed decrease in CCT of of dry eyes recorded relative to normal eyes with mean CCT of $549 \pm 34$ vs $527 \pm 30 \mu \mathrm{m}$ in dry eyes. Gunes et al. study showed the mean CCT values were significantly reduced in dry eye disease compare to normal eyes. ${ }^{5}$ Dry eye disease is the ocular surface disease causing foreign body sensation, visual disturbance and instability of the tear film. Central corneal thickness is the assessment of the corneal health. Pole and Batzer et al. study showed central corneal thickness measurement with specular microscopy is reliable. ${ }^{6}$ Reduction in CCT when there is no inflammation in patients was observed in Hovding et al. study. ${ }^{7}$ Noora Mauwafak Ali et al. dry eye disease shows significant reduction in central corneal thickness. ${ }^{2}$ Based on Koray Karadayi et al. study the CCT shows significant deference in dry eye disease. ${ }^{8}$ Based on Z Liu, S C Pflugfelder et al. study done in 1999 stated that there was a significant decrease in the corneal thickness in both central and periphery of cornea in dry eye cases. The possible cause explained as chronic state of desiccation and immune activation in dry eyes. ${ }^{9}$

\section{CONCLUSIONS}

There is a significant association between the central corneal thickness and dry eye diseases.

Data sharing statement provided by the authors is available with the full text of this article at jemds.com.

Financial or other competing interests: None.

Disclosure forms provided by the authors are available with the full text of this article at jemds.com.

\section{REFERENCES}

[1] Dilly PN. Structure and Function of the Tear Film. In: Sullivan DA, editor. Lacrimal Gland, Tear Film, and Dry Eye Syndromes: Basic Science and Clinical Relevance [Internet]. Boston, MA: Springer US; 1994 [cited 2022 Jan 9]. p. 239-47. (Advances in Experimental Medicine and Biology). Available from: https://doi.org/10.1007/978-1-4615-2417-5_41

[2] Ali NM, Hamied FM, Farhood QK. Corneal thickness in dry eyes in an Iraqi population. Clin Ophthalmol Auckl NZ. 2017 Feb 23;11:435-40.

[3] Stevens S. Schirmer's test. Community Eye Health. 2011 Dec;24(76):45.

[4] Celebi ARC, Mirza GE. Differences in Central Corneal Thickness between Spectral Domain-Optical Coherence Tomography and Ultrasound Pachymetry in Patients with Dry Eye Disease. J Ophthalmol. 2016 Jun 8;2016:e2623719.

[5] Gunes A, Inal EE, Tok L, Tok O. Evaluation of central and peripheral corneal thicknesses in patients with rheumatoid arthritis. Arq Bras Oftalmol. 2015 Aug;78(4):236-40.

[6] Módis L, Langenbucher A, Seitz B. Corneal thickness measurements with contact and noncontact specular microscopic and ultrasonic pachymetry. Am J Ophthalmol. 2001 Oct 1;132(4):517-21.

[7] Improving the Health of the Ocular Surface With Artificial Tears [Internet]. CRSToday. [cited 2021 Dec 9]. Available from: https://crstoday.com/articles/2009apr/crst0409_11-php/

[8] Fujimoto K, Inomata T, Okumura Y, Iwata N, Fujio K, Eguchi A, et al. Comparison of corneal thickness in patients with dry eye disease using the Pentacam rotating Scheimpflug camera and anterior segment optical coherence tomography. PLOS ONE. 2020 Feb 3;15(2):e0228567.

[9] Liu Z, Pflugfelder SC. Corneal thickness is reduced in dry eye. Cornea. 1999 Jul;18(4):403-7. 